Cite this: Phys. Chem. Chem. Phys., 2013 15, 16976

\title{
Comment on "On the dual emission of p-dimethylaminobenzonitrile and its photophysical implications"
}

Klaas A. Zachariasse

Received 27th May 2013,

Accepted 31st July 2013

DOI: $10.1039 /$ c3cp52225c

www.rsc.org/pccp

Recently, ${ }^{1}$ Catalán reported the dual emission of 4-(dimethylamino)benzonitrile (DMABN) in 1-chlorobutane (ClB) and 2-methylbutane (2MB) as a function of temperature. In addition, DMABN was studied in two solvent mixtures: 2MB-ClB 80/20 (v/v) at a series of temperatures and methyl acetate-acetonitrile (MeCN) (seven isoviscous mixtures between 90/10 and 30/70 (v/v)) at $25{ }^{\circ} \mathrm{C}$. From a thermochromic analysis of the maxima of the locally excited (LE) and intramolecular charge transfer (ICT) fluorescence bands of DMABN, the following dipole moments were deduced: $\mu_{\mathrm{e}}(\mathrm{LE})=6.7 \mathrm{D}$ and $\mu_{\mathrm{e}}(\mathrm{ICT})=9.4 \mathrm{D}^{1}{ }^{1}$ It was noticed that these values were much smaller than those derived in the literature from solvatochromic (not thermochromic) measurements, which are 14 to $23 \mathrm{D}$ for $\mu_{\mathrm{e}}$ (ICT). From time-resolved microwave conductivity (TRMC) experiments, not mentioned in ref. 1, much larger dipole moments were obtained: $\mu_{\mathrm{e}}(\mathrm{LE})=9.7 \mathrm{D}$ and $\mu_{\mathrm{e}}(\mathrm{ICT})=17.4 \mathrm{D}^{2}$

Catalán then claimed that his results $\mu_{\mathrm{e}}(\mathrm{LE})=6.7 \mathrm{D}$ and $\mu_{\mathrm{e}}(\mathrm{ICT})=9.4 \mathrm{D}$ were in good agreement with those determined in ref. 69, interpreted as $\mu_{\mathrm{e}}(\mathrm{LE})=7.9 \mathrm{D}$ and $\mu_{\mathrm{e}}(\mathrm{ICT})=10.6 \mathrm{D}$. This interpretation does, however, not appear in the paper of Pratt et al. There, the dipole moments $\mu_{\mathrm{g}}\left(\mathrm{S}_{0}\right)=7.9 \mathrm{D}$ and $\mu_{\mathrm{e}}\left(\mathrm{S}_{1}\right)=$ 10.6 $\mathrm{D}$ are reported for DMABN in the gas phase, for the ground state $S_{0}$ and the $S_{1}$ state reached directly by light absorption from $S_{0}$, not for the LE and ICT states. Note that DMABN in the gas phase does not undergo an ICT reaction, ${ }^{3}$ in other words, an ICT state is not formed and hence cannot be studied. Therefore, the treatment of Abe employed in ref. 1 (not described in the main text) does not lead to correct results.

Temperature dependence of radiative rate constants: the intensity of the fluorescence spectra of DMABN in $2 \mathrm{MB}$ strongly decreased by a factor of about 15 when going from 20 to $-160{ }^{\circ} \mathrm{C}$. Because of this unusual result, precipitation of DMABN was thought to

Max-Planck-Institut für biophysikalische Chemie, Spektroskopie und Photochemische Kinetik, 37070 Göttingen, Germany. E-mail: kzachar@gwdg.de be unlikely, due to its low concentration (below $5 \times 10^{-6} \mathrm{M}$ ). From our experience with DMABN in alkane solvents, ${ }^{4}$ however, precipitation seems to be the most likely cause, due to low solubility of DMABN in $2 \mathrm{MB}$. Further, it was said that the quantum yield of the ICT emission of DMABN in ClB increases with decreasing temperature and that this contradicts the assumption that the radiative rate constant $k_{\mathrm{f}}^{\prime}(\mathrm{ICT})$ depends on temperature. How this conclusion is reached remains unclear. In contrast, $k_{\mathrm{f}}{ }^{\prime}(\mathrm{ICT})$ and $k_{\mathrm{f}}(\mathrm{LE})$ of DMABN in MeCN show a clear temperature dependence. ${ }^{5}$ Such a dependence was also reported for excimers. ${ }^{6}$

Our PICT model: in the Introduction of ref. 1, our approach to the ICT of DMABN is discussed: 'One such model assumes rehybridization of the donor via a Jahn-Teller effect leading to pyramidalization of the amino group of DMABN in its ICT state', for which ref. 12-14 dating back to 1991-1993 are quoted. The statement that we have advocated two ICT models is incorrect, readily seen by consulting ref. 12-14. Only in 1996 our PICT model was introduced (ref. 15). This model states that there is substantial electronic coupling between the amino (D) and benzonitrile (A) moieties in the ICT state of DMABN, in contrast to the TICT model, which claims that there is no or negligible electronic overlap between D and A (principle of minimal overlap) and stresses the mutually perpendicular $\left(90^{\circ}\right)$ orientation of $\mathrm{D}$ and A. The PICT model does not take such a limiting position, emphasizing the 'substantial coupling'. Hence, the twist angle $\varphi$ between $\mathrm{D}$ and A does not have to be zero: even with $\varphi=60^{\circ}$ there can be an important electronic overlap $\left(\sim(\cos \varphi)^{2}\right)$. As a consequence, a nonzero twist angle smaller than $90^{\circ}$ is not TICT: see also the definitions of PICT and TICT in the IUPAC Glossary ${ }^{7}$ and in our ${ }^{2,5}$ papers. A second, not less important, content of the PICT model is that a sufficiently small energy gap between the two lowest excited singlet states $\Delta E\left(\mathrm{~S}_{1}, \mathrm{~S}_{2}\right)$ is an essential requirement for the occurrence of ICT, as already discussed in ref. $14 .^{8}$ 
Finally, it will be difficult to deduce useful information on the separate influence of solvent polarity and viscosity (not detailed in ref. 1) solely based on photostationary spectra, especially in solvent mixtures where preferential solvation may play a role.

\section{References}

1 J. Catalán, Phys. Chem. Chem. Phys., 2013, 15, 8811-8820.

2 W. Schuddeboom, S. A. Jonker, J. M. Warman, U. Leinhos, W. Kühnle and K. A. Zachariasse, J. Phys. Chem., 1992, 96, 10809-10819.

3 S. I. Druzhinin, P. Mayer, D. Stalke, R. Von Bülow, M. Noltemeyer and K. A. Zachariasse, J. Am. Chem. Soc., 2010, 132, 7730-7744.
4 S. I. Druzhinin, A. Demeter, V. A. Galievsky, T. Yoshihara and K. A. Zachariasse, J. Phys. Chem. A, 2003, 107, 8075-8085.

5 S. I. Druzhinin, N. P. Ernsting, S. A. Kovalenko, L. P. Lustres, T. A. Senyushkina and K. A. Zachariasse, J. Phys. Chem. A, 2006, 110, 2955-2969, and references cited therein.

6 K. A. Zachariasse, A. L. Maçanita and W. Kühnle, J. Phys. Chem. B, 1999, 103, 9356-9365, and references cited therein.

7 E. Braslavsky, Glossary of Terms Used in Photochemistry 3rd Edition, Pure Appl. Chem., 2007, 79, 293-465.

8 K. A. Zachariasse, T. von der Haar, A. Hebecker, U. Leinhos and W. Kühnle, Pure Appl. Chem., 1993, 65, 1745-1750. See corrected pages 1748 and 1749. 